\title{
Chemotherapy of Prostate Cancer by Targeted Nanoparticles Trackable by Magnetic Resonance Imaging
}

\author{
Mohamed O. Abdalla, ${ }^{1}$ Timothy Turner, ${ }^{2}$ and Clayton Yates ${ }^{2}$ \\ ${ }^{1}$ Department of Chemistry, Tuskegee University, Tuskegee, AL 36088, USA \\ ${ }^{2}$ Department of Biology and Center for Cancer Research, Tuskegee University, Tuskegee, AL 36088, USA
}

Correspondence should be addressed to Mohamed O. Abdalla, abdalla@mytu.tuskegee.edu

Received 28 March 2012; Accepted 28 May 2012

Academic Editors: R. B. Azevedo, M. Fernández-García, and K. H. Park

Copyright (C) 2012 Mohamed O. Abdalla et al. This is an open access article distributed under the Creative Commons Attribution License, which permits unrestricted use, distribution, and reproduction in any medium, provided the original work is properly cited.

\begin{abstract}
Prostate cancer $(\mathrm{CaP})$ is the commonest diagnosed malignancy and the second main cause of cancer mortality in males in the United States. Thus, there is an urgent need to develop novel drug delivery systems to improve the chemotherapy option for CaP patients. The goal of this paper is to describe novel moleculary guided nanoscale drug delivery system with dual functionality for treatment and MR imaging of CaP. We describe the synthesis of iron oxide nanoparticles (IONPs) which are then coated with carboxyl-ended amphiphilic polymer. We present the protocol for tethering of the CaP targeting protein, human amino terminal fragment (hATF) to the terminal carboxyls of the IONPs. We describe the drug loading and release and the methods for measuring of the internalization of the hATF-guided IONPs into CaP cells. We also describe the methods for usages of IONPs are MR imaging contrast agent and successful targeted drug carriers.
\end{abstract}

\section{Introduction}

Prostate cancer $(\mathrm{CaP})$ is the most prevalent noncutaneous malignancy in the United States with an estimated 192,280 new cases and 27,360 deaths in 2008 [1]. It is estimated that $\mathrm{CaP}$ alone accounts for approximately $29 \%$ of cancer cases in men, with one in six men expected to develop invasive $\mathrm{CaP}$ in his lifetime. Although the chemotherapeutic armamentarium of drugs has been a major option for treatment of advanced CaP patients [2, 3], chemotherapy has several drawbacks such as the severe cytotoxic side-effect on normally proliferating tissues [4]. In addition, development of multidrug resistance by cancer cells often leads to the eventual failure of treatment [5].

In the last two decades, there has been an exponential growth of interest in magnetic nanoparticles (MNPs) which offer unique physical properties and ability to function at the cellular and molecular level of biological interactions $[6,7]$. In particular, MNPs present exciting new opportunities including dual functionality of site-specific delivery of anticancer drugs coupled with an enhanced quality of magnetic resonance imaging (MRI) [8]. Thus, MNPs have the potential to revolutionize current clinical diagnostic and therapeutic strategies for CaP patients [9-11].

The most commonly studied MNPs are iron oxide nanoparticles (IONPs), mostly maghemite, $\gamma$ - $\mathrm{Fe}_{2} \mathrm{O}_{3}$, or magnetite, $\mathrm{Fe}_{3} \mathrm{O}_{4}[6,7,12-15]$. IONPs have become popular options for potential multifunctional drug delivery vehicles for several reasons. First, the chemistry of the surface modification for these nanoparticles is well known, and thus molecules such as targeting ligands and drugs can be conveniently tethered to their surface $[12,15-18]$. Secondly, they have been extensively used as MRI contrast agents due to their superparamagnetic property $[6,16]$. Lastly and most importantly, they are known to be biocompatible and nontoxic as upon metabolism, iron ions are added to the body's iron stores and eventually incorporated by erythrocytes as hemoglobin allowing for their safe use in vivo $[7,19]$.

To achieve optimum performance of MNPs as drug delivery vehicles, it is essential to well tailor their surface chemistry, size (magnetic core and size distribution), and magnetic properties (magnetic moment, remanence, and coercivity) [20]. There are vital reasons to modify the surface 
chemistry for MNPs so they can serve as successful drug delivery vehicles [18, 21-23]. First, these MNPs must be well dispersed in plasma for a reasonable period without aggregation which otherwise might cause severe embolization in vivo by blocking of capillary vessels. Second, nonspecific adsorption of plasma proteins onto MNPs surfaces should be prevented, as this would result in uptake of these nanoparticles by macrophages of the reticuloendothelial system in the liver and spleen. Finally, it is desirable that suitable functional groups are present on the surfaces of MNPs; as such groups are used to immobilize bioactive ligands for targeting or therapeutic purposes.

In order to be able to achieve dispersibility in an aqueous medium, the best surface modification for these NPs is coating them with an amphiphilic polymer system $[18,24]$. The amphiphilic polymer will provide the hydrophobic part which can anchor to the magnetite NPs surface while the hydrophilic portion is directed towards the aqueous environment, thus providing robust water dispersibility. Moreover, to block protein adsorption to these NPs, a hydrophilic and biocompatible polymer such as poly(ethylene glycol) (PEG) is tethered to the amphiphilic polymeric coating which increases the circulatory half-life from minutes to hours or days $[8,13,14]$.

Thus, based upon the wide variety of parameters that need to be accounted for the design, preparation, optimization, and characterization of the magnetite nanoparticles, we present here some of the techniques we have employed in our laboratory to design smart magnetic nanovehicles for targeted drug delivery. For convenience, we will refer throughout this paper to the magnetite nanoparticles as IONPs.

\section{Synthesis and Surface Modification of Iron Oxide Nanoparticles (IONPs)}

All the chemicals for the synthesis of the IONPs are obtained from Sigma-Aldrich, St. Louis, MO.

2.1. Coprecipitation Method. This is the most common chemical method for the synthesis of IONPs [25]. In this method, it is essential to control the reaction kinetics, which is strongly related with the oxidation speed of iron species. Thus, the synthesis of magnetite NPs must be done in an oxygen-free environment by passing nitrogen gas through the reaction system. Bubbling nitrogen gas through the solution not only protects critical oxidation of the magnetite but also reduces the particle size when compared with methods without removing the oxygen $[12,17]$. The procedure involves that ferric $\left(\mathrm{Fe}^{2+}\right)$ and ferrous salts $\left(\mathrm{Fe}^{3+}\right)$ (molar ratio 2:1) are dissolved in deoxygenated water at a concentration of $0.1 \mathrm{M}$ of iron ions. Chemical precipitation is achieved by using a $1 \mathrm{M}$ deoxygenated solution of sodium hydroxide. The reaction is carried out in nitrogen atmosphere at low temperature $\left(4-6^{\circ} \mathrm{C}\right)$ with vigorous stirring. Particles are washed by dialysis using Spectra/Por* $12 \mathrm{kDa}$ cut off dialysis membrane (VWR, NJ) against doubledistilled water to remove unreacted water salts. Then, the particles are precipitated with acetone and dried in vacuum oven at $70-80^{\circ} \mathrm{C}$. The surface of the particles is neutralized with $0.01 \mathrm{M} \mathrm{HCl}$. Particles are coated with sodium oleate to form the stable dispersion of the magnetite nanoparticles. A solution of $1 \mathrm{M}$ sodium oleate is prepared for coating. To the aqueous suspension of magnetic particles, sodium oleate solution is added dropwise with continuous and vigorous stirring at $60-70^{\circ} \mathrm{C}$ under nitrogen atmosphere. Excess sodium oleate is removed through rigorous dialysis using $12 \mathrm{kDa}$ cut-off dialysis membrane as described previously.

\subsection{High-Temperature Decomposition of Organometallic.} Another common chemical method to synthesize IONPs is the high-temperature decomposition of organometallic precursors $[26,27]$. This method produces IONPs with marked improvements in size control, size distributions, and crystallinity [28-30]. The procedure involves the magnetic mixing of $2 \mathrm{mmol}$ of iron acetylacetonate $\mathrm{Fe}(\mathrm{acac})_{3}, 10 \mathrm{mmol}$ of 1,2-hexadecanediol, $6 \mathrm{mmol}$ oleylamine, $6 \mathrm{mmol}$ oleic acid and $20 \mathrm{~mL}$ of benzyl under a flow of nitrogen for $20 \mathrm{~min}$. Under a blanket of nitrogen, the mixture is preheated to $120^{\circ} \mathrm{C}$ for $30 \mathrm{~min}$, and the temperature is ramped up to $200^{\circ} \mathrm{C}$ for an additional $2 \mathrm{~h}$. The final step is the refluxing of the mixture at $300^{\circ} \mathrm{C}$ for $1 \mathrm{~h}$. The black solution is allowed to cool to room temperature, and $100 \mathrm{~mL}$ of ethanol is added to it to yield black precipitate. The product can be separated by centrifugation at $6000 \mathrm{rpm}$ for $10 \mathrm{~min}$ and is dispersed in hexane in the presence of $0.05 \mathrm{~mL}$ oleic acid and oleyamine, respectively. The undissolved residue is removed by further centrifugation, and the final product is then precipitated with ethanol. Finally, the ethanol is removed by centrifugation, and the final product is redispersed into hexane.

2.3. Characterization of IONPs. The synthesized IONPs are characterized by X-ray diffraction (Rigaku D/MAX2000, Houston, TX). NPs dispersed in hexane are deposited on a glass holder, the solvent is evaporated, and the sample is scanned $2-\theta$ scan rate of $2^{\circ} / \mathrm{min}$ over the range 2 to $80^{\circ}$ with $\mathrm{Cu} \mathrm{K} \alpha$ radiation $(\lambda=1.54184 \AA)$. Our results show that the synthesized IONPs have six diffraction peaks at $2 \theta=29.99,35.4,43,57,62.5$ (degrees) which correlate well with the characteristics peaks of standard $\mathrm{Fe}_{3} \mathrm{O}_{4}$ crystal (isometric-hexaoctahedral crystal pattern) (Figure 1) [28, 31]. The size and morphology of the synthesized NPs are determined from their transmission electronic microscopy micrographs. Samples for the TEM experiments are prepared by suspending a dried sample in absolute ethanol. A drop of the sample suspension is allowed to dry on a 400-mesh copper grid (Electron Microscopy Sciences, PA) coated with a carbon film. Particles are imaged using a JEOL-JEM 100 SX electron microscope (JEOL, CA) at an accelerating voltage of $200 \mathrm{kV}$. It can be observed from Figure 1(b) that the IONPs nanocrystals are relatively uniform with an average size of $10 \mathrm{~nm}[27,28,30]$. The magnetic properties of the synthesized IONPs under a magnetic field are evaluated by alternating gradient magnetometer (AGM) to confirm the feasibility and sensitivity as MRI nanoprobes. The field dependence of magnetization is recorded at $300 \mathrm{~K}$ under 


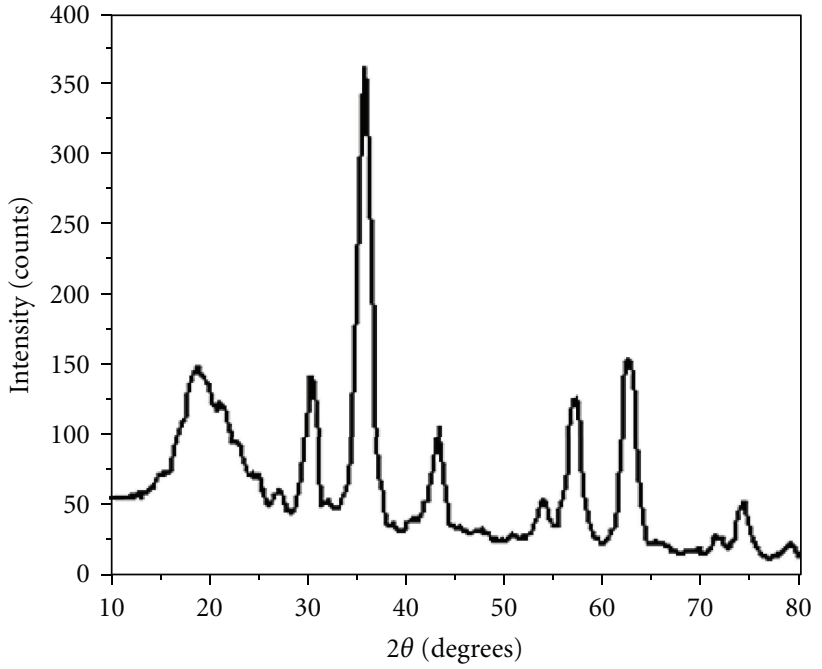

(a)

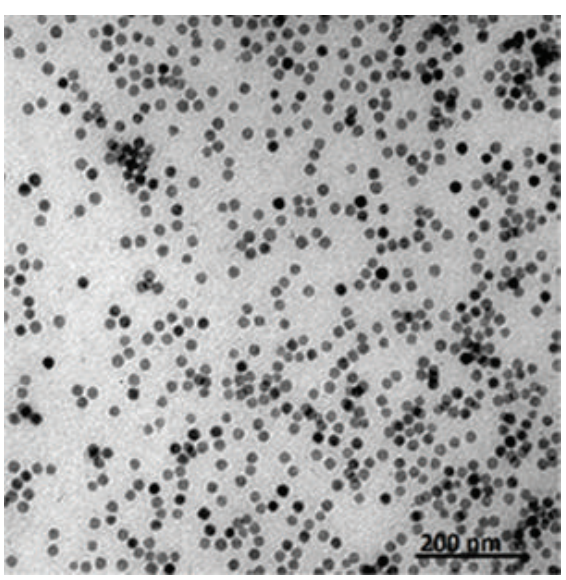

(b)

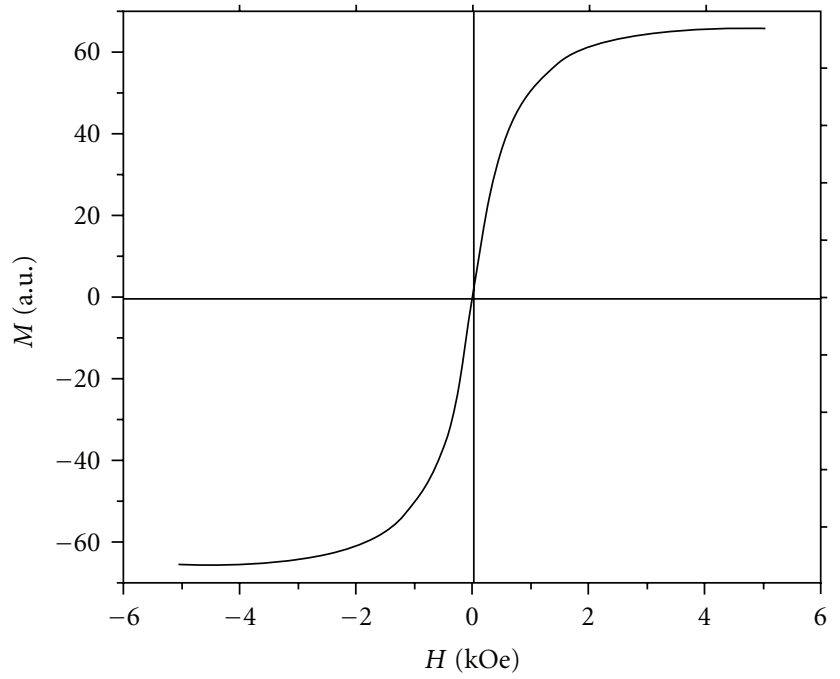

(c)

Figure 1

circulate magnetic field ranging between 2 and $-2 \mathrm{~T}$. The results showed that the IONPs exhibit superparamagnetism without magnetic hysteresis at room temperature $(300 \mathrm{~K})$ (Figure 1(c)) [27, 28, 30].

2.4. Surface Modification of IONPs by Amphiphilic Polymer. All the chemicals for the surface modification of the IONPs are obtained from Sigma-Aldrich, St. Louis, MO. The amphiphilic polymer is composed of three functional parts: hydrophobic groups for anchoring onto the IONPs surface, PEG for blocking protein adsorption, and carboxylic acid to permit the introduction of bioactive molecules $[31,32]$. First, the procedure involves the synthesis of the amphiphilic polymer as follows $[18,24]$. Dodecyl methacrylate $(4 \mathrm{mmol}$, $1.016 \mathrm{~g})$, poly(ethylene glycol) methyl ether methacrylate (PEGMA, average $M_{n}=$ ca. $475 ;(4 \mathrm{mmol}, 1.9 \mathrm{~g})$, and methacrylic acid $(2 \mathrm{mmol}, 0.172 \mathrm{~g})$ are dissolved in $10 \mathrm{~mL}$ of tetrahydrofuran (anhydrous, 99.9\%, inhibitor-free). This mixture is degassed for $15 \mathrm{~min}$ by bubbling with stream of $\mathrm{N}_{2}$ gas. After adding $0.1 \mathrm{mmol}$ of $2,2^{\prime}$-azobisisobutyronitrile $(16.4 \mathrm{mg})$ as a radical initiator, the vial is sealed with a Teflonlined screw cap. The polymerization reaction is carried out at $7^{\circ} \mathrm{C}$ for $24 \mathrm{~h}$. The final product solution is cooled to room temperature and is stored at $4^{\circ} \mathrm{C}$ until use. After the modification is completed, the IONPs concentration is determined by measuring absorbance at $A_{500}$ (Beckman DU 650 UV-VIS Spectrophotometer, CA) [9, 33]. Generally, a $10 \mathrm{mg} / \mathrm{mL}$ solution of IONPs gives an absorbance of 32.5, so generally we make sure that the absorbance values fall between 0.2 and 0.8 by using appropriate dilution, and then we use the dilution factor to estimate the final IONPs concentration based on (1):

IONPs concentration $(\mathrm{mg} / \mathrm{mL})=\frac{A_{500} \times \text { dilution factor }}{3.25}$. 


\section{Production of the Targeting Protein hATF}

To enable the selective and specific delivery of anticancer drugs to prostate cancer cells, we have taken advantage of urokinase plasminogen activator receptor (uPAR) overexpression in prostate cancer compared to normal prostate epithelia [34, 35]. Specifically, we employed the human 135 amino-acid amino-terminal fragment (hATF) of urokinase plasminogen activator ( $\mathrm{UPA})$, a high-affinity natural ligand for UPAR. The expression of the hATF is carried out as follows. The DNA sequence encoding the first 135 amino acids (with a C-terminal His-tag) of amino terminal fragment (ATF) of the human uPA that binds to uPAR is cloned into pET-20b(+) (Novagen) between EcoRI and XhoI sites of the vector [36]. These recombinant plasmids are transformed in competent TOP10F' Escherichia coli cells (Invitrogen, CA) $[36,37]$. Transformants are selected on a LB-Agar-Amp plate $50 \mu \mathrm{g} / \mathrm{mL}$ ampicillin (LB/amp agar) which is incubated at $37^{\circ} \mathrm{C}$ overnight. A colony is selected from the plate, and it is used to inoculate $25-50 \mathrm{~mL}$ sterile LB-Amp medium. The inoculate is incubated at $37^{\circ} \mathrm{C}$ at $250 \mathrm{rpm}$ for $12 \mathrm{~h}$, and the plasmid is isolated using plasmid Midi Kit (QIAGEN, $\mathrm{CA}$ ). To express target protein, the plasmid is transformed in expression bacteria BL21 cells (Invitrogen, CA). A small amount of BL21 transformation mixture is placed on an LBAgar-Amp plate and is incubated at $37^{\circ} \mathrm{C}$ overnight. Four colonies are selected and are inoculated in four different tubes with sterile $5 \mathrm{~mL}$ LB-Amp medium and then incubated overnight at $37^{\circ} \mathrm{C}$. Three hundred microliters of the overnight culture are added to 4 different fresh sterile tubes each containing $10 \mathrm{~mL}$ of sterile LB-Amp, and these tubes are incubated at $250 \mathrm{rpm}$ at $37^{\circ} \mathrm{C}$ to $\mathrm{OD}_{600}$ of $0.6-0.8$. Each culture is then split into two $5 \mathrm{~mL}$ cultures using fresh sterile tubes making a total of 8 tubes from 4 cultures. For induction of protein over expression, one tube is induced by adding $5 \mu \mathrm{L}$ of $1 \mathrm{mM}$ isopropyl-thio- $\beta$-D-galactopyranoside (IPTG), and the second tube is kept as a control (un-induced). Both the induced and uninduced tubes are incubated at $250 \mathrm{rpm}$ at $37^{\circ} \mathrm{C}$ for $4 \mathrm{~h}$. At each hour during this incubation period, $500 \mu \mathrm{L}$ aliquot from each culture ( $0 \mathrm{~h}$ samples) is removed into a microcentrifuge tube and is pelleted at $13000 \mathrm{rpm}$ for $30 \mathrm{sec}$. The supernatant is removed by aspiration, and the crude extract and purified proteins from the cultures are analyzed by SDS-PAGE followed by Coomassie brilliant blue staining. After confirming the successful expression of the hATF protein, the process is scaled up as follows. A single colony of the transformant is grown in 2.5 liter of LB medium containing $100 \mathrm{mg} / \mathrm{mL}$ of ampicillin and is incubated at $37^{\circ} \mathrm{C}$ at $250 \mathrm{rpm}$ until a measured $\mathrm{OD}_{600}$ of about $0.6-0.8$ is achieved. To induce the production of recombinant protein, IPTG is added to a final concentration of $1 \mathrm{mM}$. The cells are incubated for an additional $3 \mathrm{~h}$ at $37^{\circ} \mathrm{C}$ and finally are harvested by centrifugation at $5000 \mathrm{rpm}$ for $15 \mathrm{~min}$, and the pellet is stored at $-80^{\circ} \mathrm{C}$. To start the purification of the protein, the cell pellet is suspended in a lysis buffer ( $50 \mathrm{mM} \mathrm{Na}_{3} \mathrm{PO}_{4}, 1 \mathrm{M} \mathrm{NaCl}, 8 \mathrm{mM}$ Imidazole, $500 \mu \mathrm{L}$ Sigma's PIC (protease inhibitor cocktail)) and is cooled for $10 \mathrm{~min}$ before it is subjected to sonication for $15 \mathrm{~min}(10 \mathrm{sec}$ on, $20 \mathrm{sec}$ off, $40 \%$ amplification). The soluble and insoluble fractions are separated by centrifugation for $30-45 \mathrm{~min}$ at $15000 \mathrm{rpm}$. The supernatant is filtered using syringe and needle through 0.2 or $0.45 \mu \mathrm{m}$ filters into a fresh $50 \mathrm{~mL}$ tube. Then, $1.8 \mathrm{~mL}$ of QIAGEN Ni-Nitrilotriacetic acid (Ni-NTA) agarose beads is added to the lysate and is left to mix in a rotary mixer for $1 \mathrm{~h}$ at $4^{\circ} \mathrm{C}$. The supernatant is applied to a QIAGEN His-tag affinity column which is equilibrated with Ni-NTA buffer (50 mM Na $3 \mathrm{PO}_{4}, 1 \mathrm{M} \mathrm{NaCl}, \mathrm{pH}$ 7.9). Prior to elution, the column is first washed with $35 \mathrm{~mL}$ of $35 \mathrm{mM}$ imidazole-containing Ni-NTA buffer, and the protein is eluted twice with $1.2 \mathrm{~mL}$ of elution buffer (Ni-NTA buffer contains $250 \mathrm{mM}$ imidazole). The elutions are collected in a fresh microcentrifuge tube each time. After confirming by SDS-Page, the elutions containing the desired protein are combined, and the excess imidazole and other salts are removed from the elutions by passing through Nanosep $3 \mathrm{~K}$ centrifugal column twice at $6000 \mathrm{rpm}$ for $20 \mathrm{~min}$. The solution in the top of the column is collected in a fresh microcentrifuge tube. Sufficient amount of 10x PBS buffer (pH 7.4) (if the sample is $1.2 \mathrm{~mL}$, then $120 \mu \mathrm{L}$ is added) and protease inhibition cocktail $(1-2 \mu \mathrm{L} / \mathrm{mL})$ is added to the concentrated elution sample. The purity of the protein is determined by analyzing the protein solution by SDSPAGE. To determine the concentration of the protein in each sample, the Bradford assay (Bio-Rad, CA) is used.

3.1. Conjugation of Infrared Dye to Targeting Moiety. In order to increase the imaging capability of our targeted IONPs, the fluorescent Cy5.5 dye is conjugated to the targeting moiety, hATF, and it is recommended to wash the protein before proceeding with any conjugation. Three hundred microliters of the stock protein solution are placed into a Nanosep $3 \mathrm{~K}$ centrifugal column (Pall, Ann Arbor, MI), and $300 \mu \mathrm{L}$ of sterile water is added to it, and the mixture is centrifuged at $5000 \mathrm{rpm}$ for $20 \mathrm{~min}$. This washing step is repeated one or two more times, and generally about $300 \mu \mathrm{L}$ of the protein solution is collected into a fresh microcentrifuge tube. The conjugation of the dye to the protein is carried out based on protocol from the dye's manufacturer (GE Healthcare, $\mathrm{NJ}$ ). In an eppendorf tube, $200 \mu \mathrm{L}$ of sterile water and $200 \mu \mathrm{L}$ of 10x PBS buffer ( $\mathrm{pH} 7.8$ ) are added to $100 \mu \mathrm{L}$ of protein solution (concentration $1 \mu \mathrm{g} / \mu \mathrm{L}$ ) and mixed for $5 \mathrm{~min}$. To this solution, $1.2 \mu \mathrm{L}$ of TCEP $(0.05 \mathrm{M})$ (Sigma Aldrich, MO) is added and mixing is continued for an additional $5 \mathrm{~min}$. The dye $2.4 \mu \mathrm{L}$ of Cy5.5 monomaleimide stock solution $1 \mathrm{mg}$ of dye dissolved in $1 \mathrm{~mL}$ dimethylsulfoxide (Sigma Aldrich, $\mathrm{MO}$ ), is added to this mixture and is gently rotated at RT for $1 \mathrm{~h}$ in dark environment. Free dye molecules are separated using Nanosep $3 \mathrm{~K}$ centrifugal column, and the hATF-Cy5.5 conjugate is washed with sterile $1 \mathrm{x}$ PBS and is immediately stored at $4^{\circ} \mathrm{C}$.

3.2. Conjugation of Targeting Protein to Amphiphilic PolymerCoated IONPs. The hATF-Cy5.5 complex is conjugated to the surface of IONPs via cross-linking of carboxyl groups to amino side groups of the protein [9]. The concentration of IONPs needed for each reaction is calculated based on the size of the reaction, and a ratio of $1: 20$ of IONPs to protein-dye complex is used. Two 
hundred microliters of the activation buffer $20 \mathrm{mM}$ borate buffer, pH 5.0 (Ocean Nanotech, AR) are added to $100 \mu \mathrm{L}$ of the amphiphilic polymer-coated IONPs (concentration $5 \mathrm{mg} / \mathrm{mL}$ ). Fifty microliters of freshly prepared 1-ethyl3-[3-dimethylaminopropyl]-carbodiimide (EDAC) and $\mathrm{N}$ hydroxysulfosuccinimide (Sulfo-NHS) (Sigma Aldrich, MO) solutions are added to activate the IONPs, and the mixture is rotated gently for $20 \mathrm{~min}$. Four hundred microliters of the reaction buffer ( $10 \mathrm{mM}$ borate buffer ( $\mathrm{pH} 8.5)$, Ocean Nanotech, AR) are added to the above mixture, and the hATF-Cy5.5 complex is immediately added, and the mixture is reacted by gentle mixing in a rotary mixer at RT for $2 \mathrm{~h}$ and overnight at $4^{\circ} \mathrm{C}$. The resulting hATF-Cy5.5-IO NPs are separated from the reaction buffer using Nanosep $100 \mathrm{~K}$ centrifugal column. The NPs are purified by washing with sterile 1x PBS buffer followed by resuspension in sterile distilled water and stored at $4^{\circ} \mathrm{C}$. The mean hydrodynamic particle size and zeta potential of the various NPs are determined using dynamic laser scattering (Malvern ZetaSizer Nano ZS, Malvern Instruments, UK). Samples are prepared in a $10 \mathrm{mM}$ $\mathrm{NaCl}$ to a final concentration of $2 \mathrm{mg} / \mathrm{mL}$ and $\mathrm{pH}$ 7.4. The sample is transferred to a zeta cell (Malvern Instruments, $\mathrm{UK})$, and all measurements are made at a scattering angle of $90^{\circ}$ at $25^{\circ} \mathrm{C}$.

3.3. Loading and Release of Drug from IONPs. We have chosen noscapine (Nos) as our chemotherapeutic drug but the following procedure applies to any water-soluble drug. An aqueous solution of noscapine $(1 \mathrm{mg} / \mathrm{mL})$ is added to NTIO or hATF-Cy5.5-IO NPs at a ratio of $1 \mathrm{mg}$ drug to $3 \mathrm{mg}$ of iron $(\mathrm{Fe})$, and the mixture is rotated at RT for $4 \mathrm{~h}$ and at $4^{\circ} \mathrm{C}$ overnight. After filtration of NPs through the Nanosep $100 \mathrm{~K}$ centrifugal column, the free drug in the flow-through is analyzed by high-performance liquid chromatography (HP Agilent 1100 HPLC). A standard curve for the drug is generated using concentration range of $5-25 \mu \mathrm{g} / \mu \mathrm{L}$. A reverse phase $\mathrm{C}_{18}$ symmetry column (Symmetry $\mathrm{C}_{18}, 5 \mu \mathrm{m}$, Waters) is used as the stationary phase, and the mobile phase is a mixture of $20 \mu \mathrm{M}$ ammonium acetate solution and acetonitrile $(65: 35 \mathrm{v} / \mathrm{v})$. The injection volume is $10 \mu \mathrm{L}$, and the flow rate of the mobile phase is $1 \mathrm{~mL} / \mathrm{min}$. The column effluent is monitored at $232 \mathrm{~nm}$ with a UV detector. The encapsulation efficiency of noscapine is calculated as the mass ratio of the amount of drug entrapped in NPs to the initial amount which is used in drug loading (Table 1). Next, the release of the adsorbed drug from the surface of the amphiphilic polymer coated IO NPs is determined as follows. To simulate physiological conditions, we measure the amount of Nos that can be released from the NPs at different $\mathrm{pH}$. Slightly acidic $\mathrm{pH}$ conditions simulate the environment of the tumor interstitium while more acidic $\mathrm{pH}$ is more representative of the $\mathrm{pH}$ in intracellular vesicles such as endosomes and lysosomes. So, Nos-containing NPs are incubated in solutions of different $\mathrm{pH}(4,5,6$, or 7$)$ for $2 \mathrm{~h}$. The free drug molecules in the buffer are then separated from the NT-IO and hATF-IO-Cy5.5 NPs using Nanosep $100 \mathrm{~K}$ centrifugal column. The amount of free Nos is calculated from a standard curve of drug concentration and HPLC signal intensity.
TABle 1: Encapsulation efficiency of Nos in NT-IO and hATFCy5.5-IO NPs.

\begin{tabular}{lcc}
\hline Nanoparticles & NT-IO-Nos & hATF-Cy5.5-IO-Nos \\
\hline $\begin{array}{l}\text { \% Encapsulated drug } \\
\begin{array}{l}\text { Number of Nos } \\
\text { molecules per IO NP* }\end{array}\end{array}$ & $98.7 \pm 0.7$ & $88.2 \pm 2.3$ \\
\hline
\end{tabular}

*Total number of IONPs in each sample was derived from measuring absorption of $\mathrm{OD}_{500}$ of Fe concentration and then calculating the numbers of IONPs using (1). For example, $1 \mathrm{mg}$ of Fe equals to $0.906 \mathrm{nmol}$ of $10 \mathrm{~nm}$ IONPs. The numbers of Nos molecules in each IO nanoparticle were calculated by dividing total number of Nos with the total number of IONPs in each sample. Data from Abdalla et al. [30].

\section{Internalization of IONPs by CaP Cells}

4.1. Prussian Blue Staining. Prussian blue staining is used to confirm presence of iron in cells treated with targeted or nontargeted IONPs. In 12-well culture plates, PC-3, uPAR siRNA transfected PC-3 cells and LNCaP cells are plated and are grown in RPMI-1640 medium (supplemented with $10 \%$ fetal bovine serum (FBS)) at $37^{\circ} \mathrm{C}$ with $5 \% \mathrm{CO}_{2}$ for $24 \mathrm{~h}$. When the cells are about $80 \%$ confluent, the medium is removed and replaced with FBS-free RPMI medium which contains $30 \mathrm{pmole} / \mathrm{mL}$ of NT-IO or hATF-Cy5.5-IO NPs and incubated for an extra $4 \mathrm{~h}$. The medium is removed, and the cells are washed twice with 1x PBS and fixed using $4 \%$ formaldehyde solution. The fixed cells are stained using Prussian blue solution prepared by mixing equal amounts of $5 \%$ potassium ferrocyanide and $5 \% \mathrm{HCl}$ for $4 \mathrm{~h}$ at RT. Bright field images are obtained, and blue-stained cells were quantified and represented as percentage of positive cells compared to total number of cells (Figure 2(a)).

4.2. In Vitro MRI Scan. In $100 \mathrm{~mm}$ cell-culture plates (Corning, Corning, NY), PC-3 and LNCaP are incubated in RPMI1640 medium (supplemented with $4 \mathrm{mM} \mathrm{L}$-glutamine and $10 \% \mathrm{FBS}$ ) at $37^{\circ} \mathrm{C}$ with $5 \% \mathrm{CO}_{2}$. HEK 293 cells are used as an additional control and are incubated with Dulbecco's modified Eagle medium (DMEM) (supplemented with $4 \mathrm{mM} \mathrm{L-}$ glutamine and $10 \%$ FBS) in the same conditions. When the cells are at $80 \%$ confluent, the medium for the three cell types is removed and is replaced with medium treated with 40 picomole/mL of hATF-Cy5.5-IO. The NT-IO NPs are used as control. The cells are incubated at $37^{\circ} \mathrm{C}$ for an additional $4 \mathrm{~h}$. As the incubation is complete, the medium is removed, and the cells are then washed twice with $1 \mathrm{x}$ PBS. Then, cells are trypsinized and are collected with minimum amount of liquid. The cells are then embedded evenly in a freshly prepared $1 \%$ agarose in $1.5 \mathrm{~mL}$ eppendorf tubes. The samples are scanned using a 3-T MRI scanner (Siemens Healthcare, PA) using $T_{1}$-weighted gradient echo and multiecho $T_{2}$ weighted fast-spin echo imaging sequences. $T_{2}$ values of each sample are calculated from obtained multiecho $\left(\mathrm{TE}_{i}, i=20\right.$, range from 10 to $200 \mathrm{~ms}$, interval $=10 \mathrm{~ms}$ ). Transverse relaxation times, $T_{2}$, of each sample are calculated by fitting decay curve on a pixel-by-pixel basis using the nonlinear monoexponential algorithm of $M_{i}=M_{0} * \exp \left(-\mathrm{TE}_{i} / T_{2}\right)$, in which $M_{0}$ is the MRI signal intensity at TE of 0 , and $M_{i}$ is the MRI signal intensity at a selected TE (Figure 2(b)). 

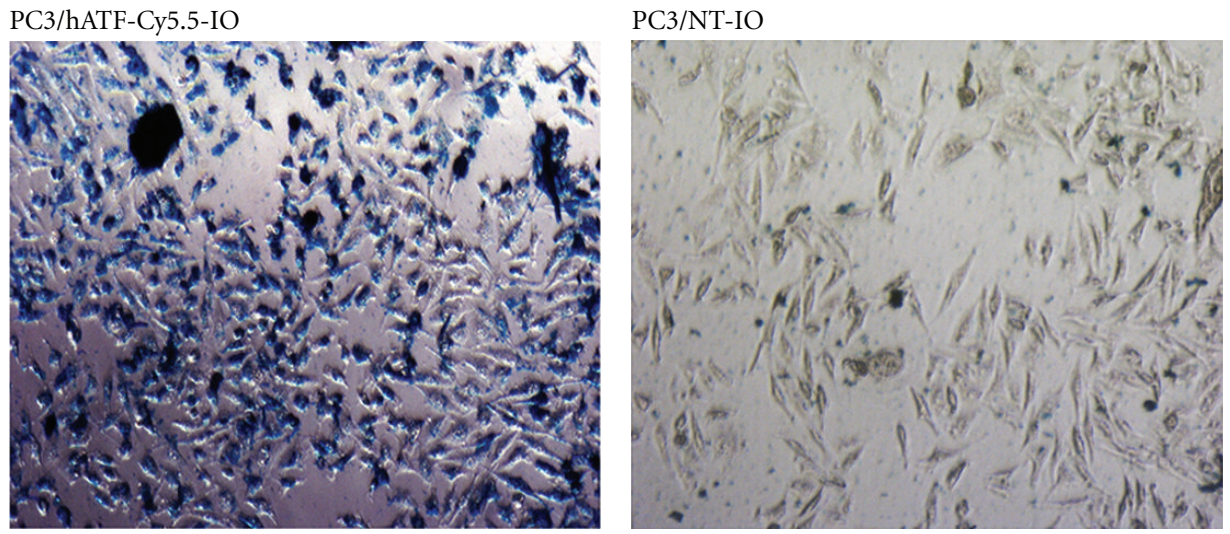

PC3/hATF-Cy5.5-IO

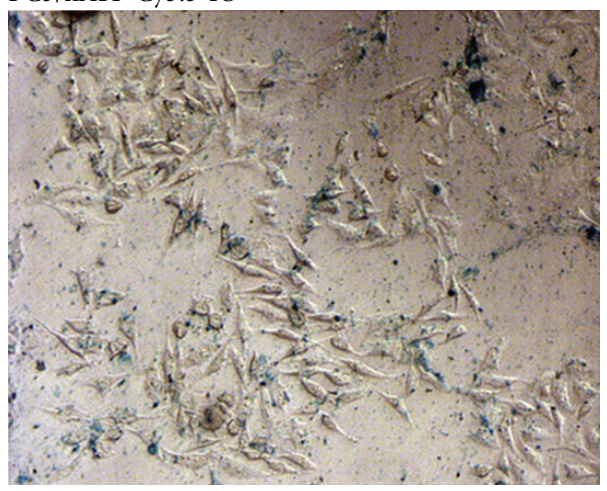

LNCaP/hATF-Cy5.5-IO

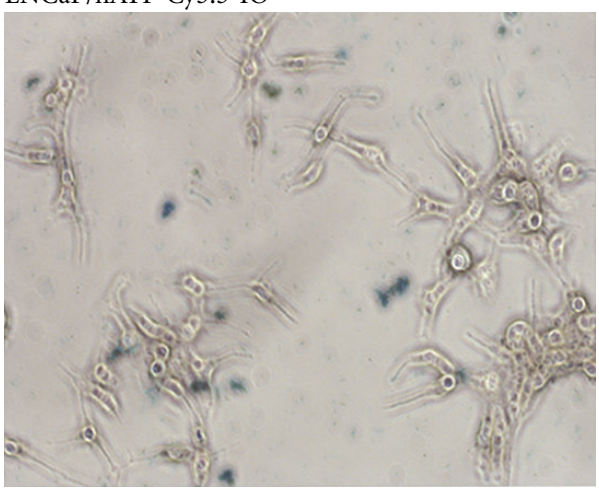

(a)

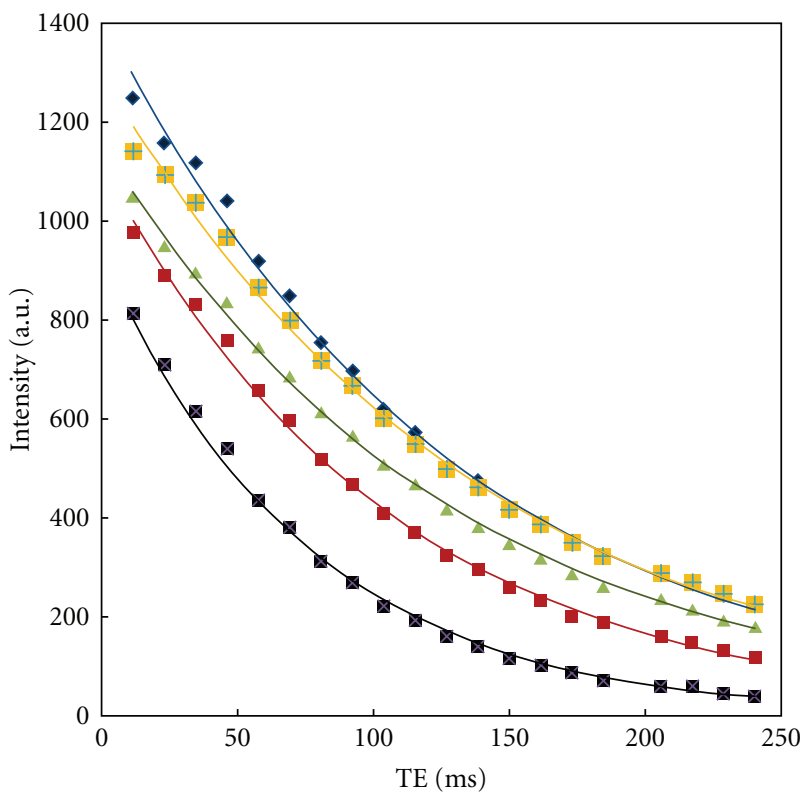

- PC3-only

- PC3-NTIO

$\triangle$ LnCAP-hATFCy5.5IO

ه PC3-hATFCy5.5IO

* HEK293-hATF-Cy5.5IO

(b)

FIgURe 2 


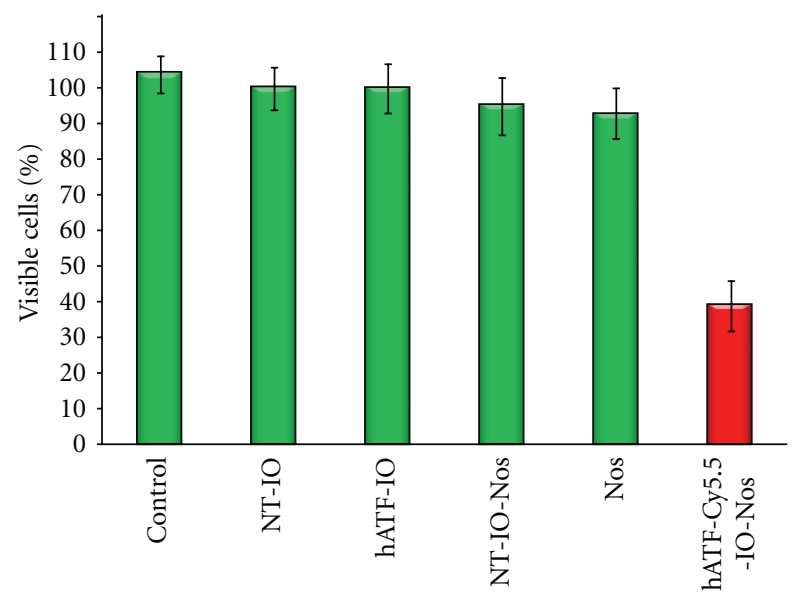

(a)

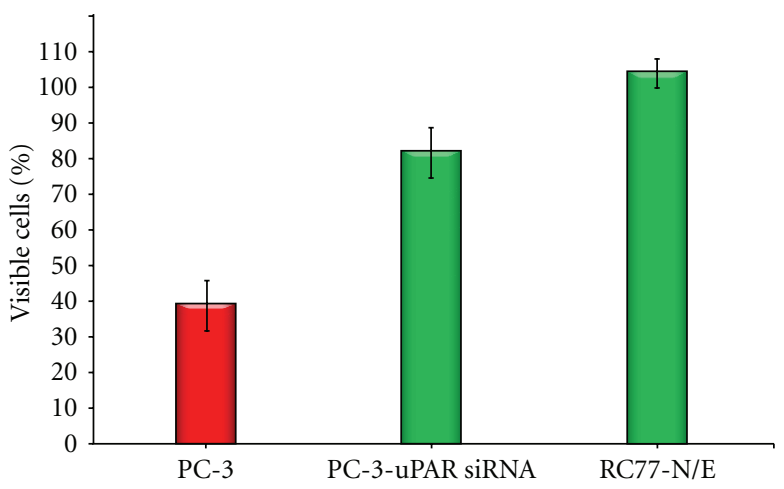

(c)

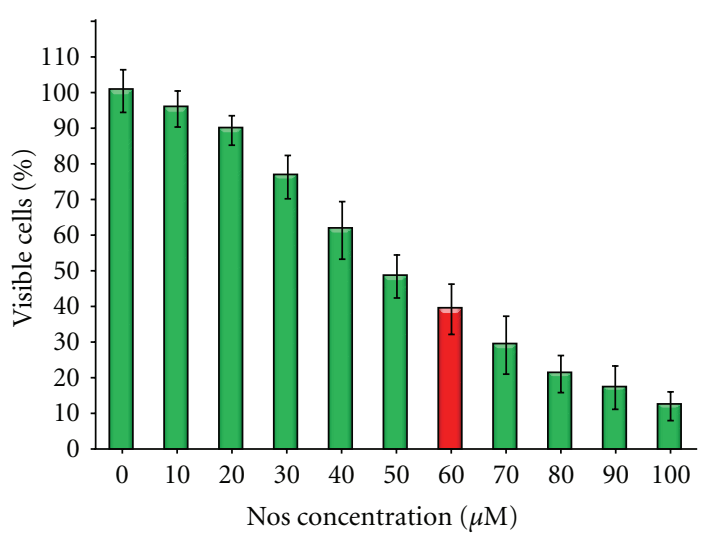

(b)

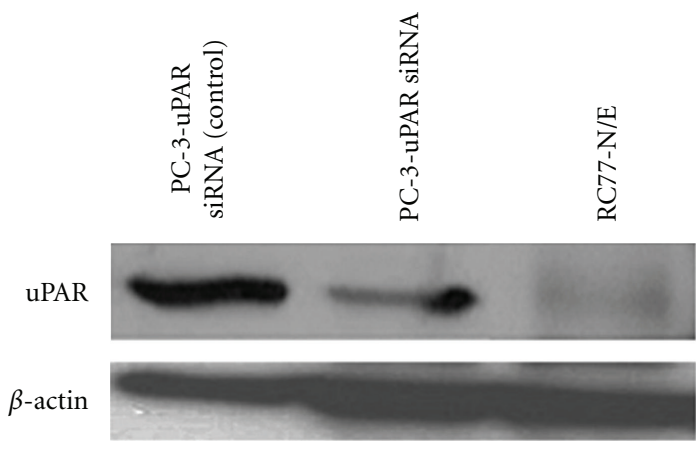

(d)

Figure 3

\section{Knockdown of uPAR Expression in PC-3 Cells}

uPAR gene expression in PC-3 cells is knocked down using human uPAR siRNA (h) kit from Santa Cruz Biotechnology Inc, CA. In a 6-well culture plate (Corning, Corning, NY), $2 \times 10^{5}$ cells per well in $2 \mathrm{~mL}$ antibiotic free RPMI-1640 supplemented with FBS. The cells are incubated at $37^{\circ} \mathrm{C}$ and $5 \% \mathrm{CO}_{2}$ until the cells are $60-80 \%$ confluent. For each transfection, two solutions are prepared in two tubes: solution $\mathrm{A}$ is prepared by diluting $4 \mu \mathrm{L}$ of siRNA duplex diluted in $100 \mu \mathrm{L}$ siRNA transfection medium, and solution $\mathrm{B}$ is prepared by diluting $4 \mu \mathrm{L}$ of siRNA transfection reagent into $100 \mu \mathrm{L}$ siRNA transfection medium. Solution $\mathrm{A}$ is added to solution $\mathrm{B}$ and mixed gently by pipetting the mixture up and down, and the mixture is incubated for $30 \mathrm{~min}$ at RT. As a negative control, the same solutions above were prepared except using control siRNA-A which consists of scrambled sequence that will not lead to specific degradation of any known cellular mRNA. The medium is removed from each well, and the cells are washed with $2 \mathrm{~mL}$ of siRNA transfection medium which is gently removed by aspiration. Immediately following the cells washing, solution $\mathrm{A}$ and solution B from the siRNA duplex or control siRNA-A prepared above are added to $0.8 \mathrm{~mL}$ of siRNA transfection medium, and the mixture is overlaid onto the washed cells. The cells are incubated for $5-7 \mathrm{~h}$ at $37^{\circ} \mathrm{C}$ and $5 \% \mathrm{CO}_{2}$, and $1 \mathrm{~mL}$ of the normal growth medium (RPMI-1640) containing 2 times the serum concentration is added to each well, and the cells are incubated for an additional $24 \mathrm{~h}$. Then, the medium is aspirated and is replaced with RPMI-1640 supplemented with regular amount of FBS and the cells are incubated for an additional $48 \mathrm{~h}$. After $72 \mathrm{~h}$ of transfection, cells are washed with 1x PBS, and are lysed in $300 \mu \mathrm{L}$ of lysis buffer. The cells are scraped off the plate, and the extract is transferred to a microcentrifuge tube and it is kept in ice. Cells are sonicated for $10-15 \mathrm{sec}$ for complete lysis, and $20 \mu \mathrm{L}$ of the mixture is then heated to $95-100^{\circ} \mathrm{C}$ for $5 \mathrm{~min}$ and again cooled on ice. After centrifugation for $5 \mathrm{~min}$, the protein is separated using SDS-PAGE gel, and then they are electrotransferred to polyvinylidene difluoride (PVDF) membranes (Bio-Rad, Hercules, CA). The membrane is blocked in phosphate-buffered saline (PBS) solution (1x TBS, $0.1 \%$ Tween-20 with 5\% w/v nonfat dry milk) milk for $1 \mathrm{~h}$ at RT and washed three times for 5 minutes each with $15 \mathrm{~mL}$ of Tris-buffered TBS/T (1x TBS, 0.1\% Tween20). The membrane is incubated with primary antibody anti-uPAR (American Diagnostics Inc., Greenwich, CT) at a $1: 1000$ dilution in TBS/T (1x TBS, $0.05 \%$ Tween-20) with gentle agitation overnight at $4^{\circ} \mathrm{C}$. The membrane is washed three times with TBST/T and is incubated with horseradish peroxidase-conjugated secondary antibody (Biomeda, Foster City, CA) in $10 \mathrm{~mL}$ of blocking buffer with gentle agitation 
for one hour at RT. The membrane is washed three times for $5 \mathrm{~min}$ each with $15 \mathrm{~mL}$ of TBS/T. The immunoreactive proteins are detected by chemiluminescence (Cell Signaling Technology, Inc., Danvers, MA) as follows. The membrane is incubated with $10 \mathrm{~mL}$ LumiGLO $(0.5 \mathrm{~mL} 20 \mathrm{x}$ LumiGLO, $0.5 \mathrm{~mL} 20 \mathrm{x}$ Peroxide and $9.0 \mathrm{~mL}$ deionized water) with gentle agitation for one minute at RT. The membrane is drained of excess developing solution, and it is wrapped in plastic wrap and is exposed to X-ray film.

\section{In Vitro Cytotoxicity Assay}

In a 96-well culture plate (Corning, Corning, NY), PC-3 and UPAR siRNA transfected cells are seeded at a density of $1 \times 10^{4}$ cells per well and are incubated at $37^{\circ} \mathrm{C}$ and $5 \% \mathrm{CO}_{2}$ for $24 \mathrm{~h}$. Normal prostate epithelia, RC-77N/E, are used as an additional control, and they are seeded at the same density and are incubated at the same conditions. RC-77N/E cells are maintained in Gibco Keratinocyte-SFM medium supplemented with EGF (human recombinant) and bovine pituitary extract (Invitrogen, Carlsbad, CA). Cells are treated with serum-free medium containing NTIO-Nos or hATF-Cy5.5-IO-Nos NPs, or free Nos $(10 \mu \mathrm{M})$. Additional control groups are treated with NT-IO or hATFIO-NPs without Nos, but these control groups have equal amounts of IO as test samples. Cells are incubated with these treatments for $4 \mathrm{~h}$ then the serum is added to the medium, and incubation is continued for an additional $48 \mathrm{~h}$. Percentage of tumor cell death is determined by crystal violet assay as follows. The medium is carefully removed from all the wells, and they are washed with $200 \mu \mathrm{L} \mathrm{1x}$ PBS which is warmed to room temperature. Then, carefully the PBS is removed, and $50 \mu \mathrm{L}$ of crystal violet solution $(0.2 \mathrm{~g}$ crystal violet, $2 \mathrm{~mL}$ ethanol, $98 \mathrm{~mL} \mathrm{dH}_{2} \mathrm{O}$ ) is added to each well, and the cells are incubated for $10 \mathrm{~min}$ at RT. The plates are gently washed twice in tap water by immersion in a large beaker. The excess water is drained by placing the plates on papers and left to air dry. $100 \mu \mathrm{L}$ of $1 \%$ SDS is added to each well to solubilize the stain, and the plates are agitated on orbital shaker until color is uniform with no areas of dense coloration in bottom of wells. The optical density is at $590 \mathrm{~nm}$ using a microplate reader (SpectroMax, Molecular Devices). Absorbance values were normalized to control values to obtain the percentage of viable cells. The uPAR-targeted NPs have 6-fold enhancement in cell death compared to the free drug (Figure 3 ).

\section{References}

[1] A. Jemal, R. Siegel, E. Ward, Y. Hao, J. Xu, and M. J. Thun, "Cancer statistics, 2009," CA: Cancer Journal for Clinicians, vol. 59, no. 4, pp. 225-249, 2009.

[2] W. Berry and M. Eisenberger, "Achieving treatment goals for hormone-refractory prostate cancer with chemotherapy," Oncologist, vol. 10, no. 3, pp. 30-39, 2005.

[3] S. Chowdhury, S. Burbridge, and P. G. Harper, "Chemotherapy for the treatment of hormone-refractory prostate cancer," International Journal of Clinical Practice, vol. 61, no. 12, pp. 2064-2070, 2007.
[4] S. K. Sahoo, W. Ma, and V. Labhasetwar, "Efficacy of transferrin-conjugated paclitaxel-loaded nanoparticles in a murine model of prostate cancer," International Journal of Cancer, vol. 112, no. 2, pp. 335-340, 2004.

[5] J. P. Van Brussel, G. Jan Van Steenbrugge, C. Van Krimpen et al., "Expression of multidrug resistance related proteins and profliferative activity is increased in avanced clinial prostate cancer," The Journal of Urology, vol. 165, pp. 130-135, 2001.

[6] D. Pouliquen, J. J. Le Jeune, R. Perdrisot, A. Ermias, and P. Jallet, "Iron oxide nanoparticles for use as an MRI contrast agent: pharmacokinetics and metabolism," Magnetic Resonance Imaging, vol. 9, no. 3, pp. 275-283, 1991.

[7] E. Okon, D. Pouliquen, P. Okon et al., "Biodegradation of magnetite dextran nanoparticles in the rat: a histologic and biophysical study," Laboratory Investigation, vol. 71, no. 6, pp. 895-903, 1994.

[8] R. Weissleder, A. Bogdanov, E. A. Neuwelt, and M. Papisov, "Long-circulating iron oxides for MR imaging," Advanced Drug Delivery Reviews, vol. 16, no. 2-3, pp. 321-334, 1995.

[9] M. O. Abdalla, P. Karna, H. K. Sajja et al., "Enhanced noscapine delivery using uPAR-targeted optical-MR imaging trackable nanoparticles for prostate cancer therapy," Journal of Controlled Release, vol. 149, no. 3, pp. 314-322, 2011.

[10] M. K. Yu, D. Kim, I. H. Lee, J. S. So, Y. Y. Jeong, and S. Jon, "Image-guided prostate cancer therapy using aptamerfunctionalized thermally cross-linked superparamagnetic iron oxide nanoparticles," Small, vol. 7, no. 15, pp. 2241-2249, 2011.

[11] Y. Ling, K. Wei, Y. Luo, X. Gao, and S. Zhong, "Dual docetaxel/superparamagnetic iron oxide loaded nanoparticles for both targeting magnetic resonance imaging and cancer therapy," Biomaterials, vol. 32, no. 29, pp. 7139-7150, 2011.

[12] D. K. Kim, Y. Zhang, W. Voit, K. V. Rao, and M. Muhammed, "Synthesis and characterization of surfactant-coated superparamagnetic monodispersed iron oxide nanoparticles," Journal of Magnetism and Magnetic Materials, vol. 225, no. 1-2, pp. 30-36, 2001.

[13] Y. X. J. Wang, S. M. Hussain, and G. P. Krestin, "Superparamagnetic iron oxide contrast agents: physicochemical characteristics and applications in MR imaging," European Radiology, vol. 11, no. 11, pp. 2319-2331, 2001.

[14] P. Tartaj, M. Del Puerto Morales, S. Veintemillas-Verdaguer, T. González-Carreño, and C. J. Serna, "The preparation of magnetic nanoparticles for applications in biomedicine," Journal of Physics D, vol. 36, no. 13, pp. R182-R197, 2003.

[15] A. K. Gupta and M. Gupta, "Synthesis and surface engineering of iron oxide nanoparticles for biomedical applications," Biomaterials, vol. 26, no. 18, pp. 3995-4021, 2005.

[16] A. K. Gupta and M. Gupta, "Synthesis and surface engineering of iron oxide nanoparticles for biomedical applications," Biomaterials, vol. 26, no. 18, pp. 3995-4021, 2005.

[17] A. K. Gupta and A. S. G. Curtis, "Lactoferrin and ceruloplasmin derivatized superparamagnetic iron oxide nanoparticles for targeting cell surface receptors," Biomaterials, vol. 25, no. 15, pp. 3029-3040, 2004.

[18] J. Park, M. K. Yu, Y. Y. Jeong et al., “Antibiofouling amphiphilic polymer-coated superparamagnetic iron oxide nanoparticles: synthesis, characterization, and use in cancer imaging in vivo," Journal of Materials Chemistry, vol. 19, no. 35, pp. 6412-6417, 2009.

[19] R. Weissleder, D. D. Stark, B. L. Engelstad et al., "Superparamagnetic iron oxide: pharmacokinetics and toxicity," American Journal of Roentgenology, vol. 152, no. 1, pp. 167-173, 1989. 
[20] P. A. Voltairas, D. I. Fotiadis, and L. K. Michalis, "Hydrodynamics of magnetic drug targeting," Journal of Biomechanics, vol. 35, no. 6, pp. 813-821, 2002.

[21] T. K. Jain, S. P. Foy, B. Erokwu, S. Dimitrijevic, C. A. Flask, and V. Labhasetwar, "Magnetic resonance imaging of multifunctional pluronic stabilized iron-oxide nanoparticles in tumor-bearing mice," Biomaterials, vol. 30, no. 35, pp. 6748-6756, 2009.

[22] L. Sun, C. Huang, T. Gong, and S. Zhou, "A biocompatible approach to surface modification: biodegradable polymer functionalized super-paramagnetic iron oxide nanoparticles," Materials Science and Engineering C, vol. 30, no. 4, pp. 583$589,2010$.

[23] M. Mahmoudi, S. Sant, B. Wang, S. Laurent, and T. Sen, "Superparamagnetic iron oxide nanoparticles (SPIONs): development, surface modification and applications in chemotherapy," Advanced Drug Delivery Reviews, vol. 63, no. 1-2, pp. 24-46, 2011.

[24] S. Park, H. S. Yang, D. Kim, K. Jo, and S. Jon, "Rational design of amphiphilic polymers to make carbon nanotubes waterdispersible, anti-biofouling, and functionalizable," Chemical Communications, no. 25, pp. 2876-2878, 2008.

[25] R. Massart, "Preparation of aqueous magnetic liquids in alkaline and acidic media," IEEE Transactions on Magnetics, vol. 17, no. 2, pp. 1247-1248, 1981.

[26] S. Sun and H. Zeng, "Size-controlled synthesis of magnetite nanoparticles," Journal of the American Chemical Society, vol. 124, no. 28, pp. 8204-8205, 2002.

[27] S. Sun, H. Zeng, D. B. Robinson et al., "Monodisperse $\mathrm{MFe}_{2} \mathrm{O}_{4}$ ( $\mathrm{M}=\mathrm{Fe}, \mathrm{Co}, \mathrm{Mn})$ nanoparticles," Journal of the American Chemical Society, vol. 126, no. 1, pp. 273-279, 2004.

[28] F. X. Hu, K. G. Neoh, and E. T. Kang, "Synthesis and in vitro anti-cancer evaluation of tamoxifen-loaded magnetite/PLLA composite nanoparticles," Biomaterials, vol. 27, no. 33, pp. 5725-5733, 2006.

[29] V. Závišová, M. Koneracká, O. Štrbák et al., "Encapsulation of indomethacin in magnetic biodegradable polymer nanoparticles," Journal of Magnetism and Magnetic Materials, vol. 311, no. 1, pp. 379-382, 2007.

[30] M. O. Abdalla, R. Aneja, D. Dean et al., "Synthesis and characterization of noscapine loaded magnetic polymeric nanoparticles," Journal of Magnetism and Magnetic Materials, vol. 322, no. 2, pp. 190-196, 2010.

[31] R. M. Cornell and U. Schwertmann, The Iron Oxides: Structure, Properties, Reactions, Occurrence and Uses, Wiley-VCH, New York, NY, USA, 1996.

[32] C. Corot, P. Robert, J. M. Idée, and M. Port, "Recent advances in iron oxide nanocrystal technology for medical imaging," Advanced Drug Delivery Reviews, vol. 58, no. 14, pp. 14711504, 2006.

[33] L. Yang, X. Qian, H. Mao et al., "Development of receptor targeted magnetic iron oxide nanoparticles for efficient drug delivery and tumor imaging," Journal of Biomedical Nanotechnology, vol. 4, pp. 1-11, 2008.

[34] S. M. Pulukuri, C. S. Gondi, S. S. Lakka et al., "RNA interference-directed knockdown of urokinase plasminogen activator and urokinase plasminogen activator receptor inhibits prostate cancer cell invasion, survival, and tumorigenicity in vivo," Journal of Biological Chemistry, vol. 280, no. 43, pp. 36529-36540, 2005.

[35] Y. Li and P. J. Cozzi, "Targeting uPA/uPAR in prostate cancer," Cancer Treatment Reviews, vol. 33, no. 6, pp. 521-527, 2007.

[36] K. S. Kim, Y. K. Hong, Y. Lee et al., "Differential inhibition of endothelial cell proliferation and migration by urokinase subdomains: amino-terminal fragment and kringle domain," Experimental and Molecular Medicine, vol. 35, no. 6, pp. 578585, 2003.

[37] K. S. Kim, Y. K. Hong, Y. A. Joe et al., "Anti-angiogenic activity of the recombinant kringle domain of urokinase and its specific entry into endothelial cells," Journal of Biological Chemistry, vol. 278, no. 13, pp. 11449-11456, 2003. 

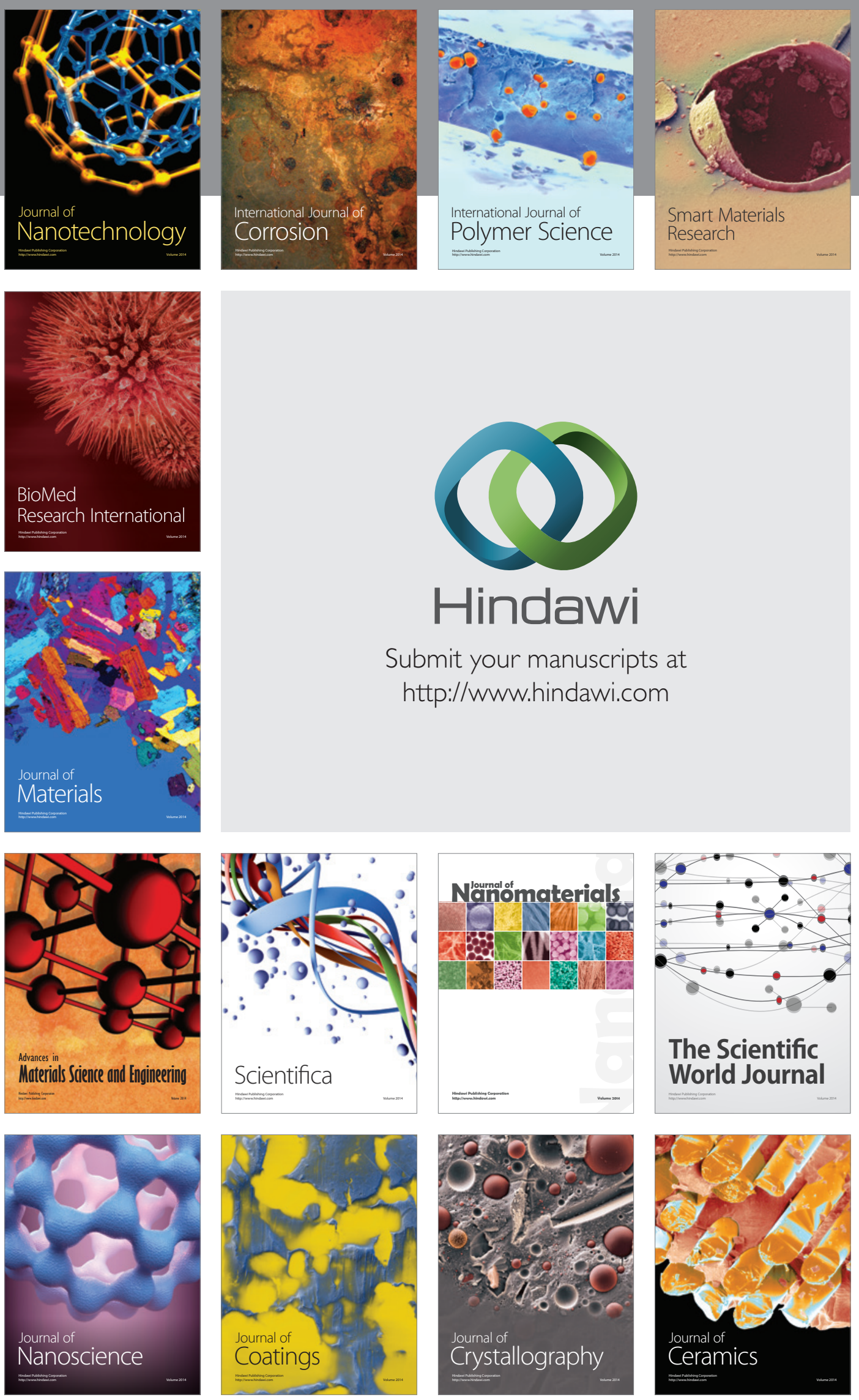

The Scientific World Journal

Submit your manuscripts at

http://www.hindawi.com

\section{World Journal}

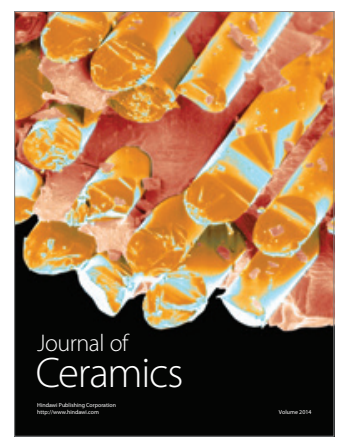

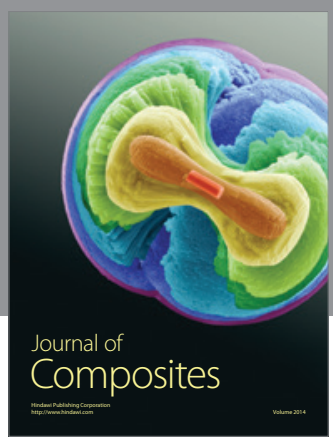
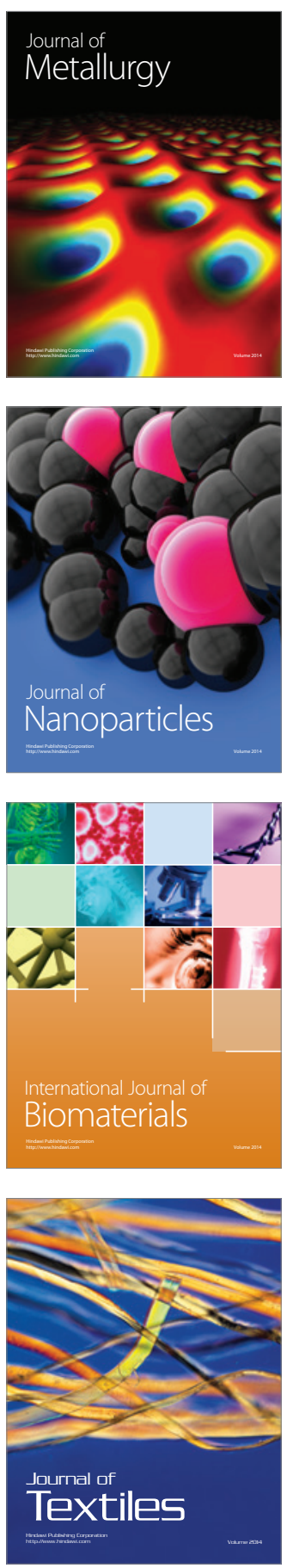